\title{
Endoscopic ultrasound: a useful tool to assess the mediastinum in patients with lung cancer?
}

\section{Penman, R J Fergusson}

\section{EUS-FNA may help to diagnose the spread of lesions to the mediastinum in patients with lung cancer.}

M ediastinal involvement either by direct invasion or by spread to lymph nodes is seen at diagnosis in up to $50 \%$ of patients with non-small cell lung cancer and has a significant impact on both treatment and prognosis. Ipsilateral or subcarinal lymph node involvement (N2 disease) is associated with a 5 year survival of $7-13 \%^{1}$ and usually precludes resection, but may identify a subset of patients who might benefit from neoadjuvant therapy. Contralateral nodal disease (N3) is surgically incurable with fewer than 5\% of patients surviving 5 years. Accurate assessment of the mediastinum at the time of diagnosis is therefore vital for patients deemed suitable for potentially curative treatment.

To date, computed tomographic (CT) scanning remains the mainstay of imaging the mediastinum but it has limited sensitivity and specificity for detecting nodal involvement. Enlarged benign reactive nodes are frequently present in patients with a lung primary and, conversely, micrometastasis may exist in "normal" sized nodes. ${ }^{23}$ Thus, the finding of nodes greater than $1 \mathrm{~cm}$ on CT scanning usually leads to mediastinoscopy or anterior mediastinotomy to obtain histological proof of involvement. These procedures are invasive, require general anaesthesia, and have a small (1-3\%) complication rate. Mediastinoscopy alone may also provide limited access to the subcarinal space and posterior mediastinum. By contrast, in 10$12 \%$ of patients with apparently negative preoperative CT scans, mediastinal nodal disease is discovered at operation. ${ }^{3}$

Endoscopic ultrasound (EUS) is a technique which has been in clinical practice for two decades and is a well established part of gastrointestinal endoscopy in many countries. By using a modified endoscope with an ultrasound transducer on its tip, unparalleled views of the gastrointestinal wall layers and the structures adjacent to the gut lumen may be obtained. Scanning from the oesophagus provides excellent views of the subcarina (level 7), aortopulmonary window (level 5), and posterior mediastinum where it is possible to resolve lymph nodes as small as $3-4 \mathrm{~mm}$. Artefact associated with air in the trachea, however, greatly limits views of the paratracheal regions and anterior mediastinum. The use of curved linear array echoendoscopes allows real time visualisation of the passage of a needle, allowing safe and accurate fine needle aspiration (FNA) sampling of masses or lymph nodes adjacent to the gut lumen.

Numerous studies in recent years, reported predominantly in the gastrointestinal literature, have demonstrated the superiority of EUS over CT scanning for the detection of mediastinal node involvement. ${ }^{4-6}$ While sonographic criteria (large hypoechoic round nodes with discrete borders) may suggest malignancy, imaging alone cannot reliably differentiate benign reactive nodes from malignant ones. When FNA sampling is added, the sensitivity for detection of malignancy is $81-91 \%$ with an overall accuracy of $90-95 \%{ }^{4-10}$ In a significant proportion of patients EUS-FNA also provides the primary tissue diagnosis, especially when other methods have failed. Few studies have directly compared this technique with transbronchial needle aspiration, but available evidence suggests that the EUS-FNA method is simpler and more likely to yield a tissue diagnosis with fewer complications. ${ }^{11}$ However, EUS-FNA is not yet available to most respiratory physicians in the UK who are involved in the diagnosis and staging of patients with lung cancer.

In this issue of Thorax Larsen et al describe the role of EUS guided biopsy in two groups of patients with suspicious mediastinal masses. ${ }^{12}$ In 34 patients with known lung cancer the authors confirm the results of earlier studies with a specificity of $100 \%$ and only two false negative FNA results. In one of these patients a subsequent mediastinoscopy was also negative, with both requiring a thoracotomy to prove malignancy. Perhaps the more interesting data concern the second group of 50 patients with mediastinal masses or lymphadenopathy discovered on CT scanning but without intrapulmonary abnormality or other suspicion of lung cancer. In 36 (72\%) EUS-FNA demonstrated mediastinal malignancy (N2/N3 or T4 disease) and in seven of these the cytological examination revealed small cell cancer leading to subsequent referral for chemotherapy. Of the 14 patients with a negative FNA result, three were subsequently found to have malignancy on either follow up, mediastinoscopy, or thoracotomy (one case each). Perhaps reassuringly, all five patients in both groups who were found to have inconclusive cytological findings were subsequently found to have no evidence of malignancy on prolonged follow up. There were no procedure related complications.

So far so good, but how does this information affect clinical decision making and patient management? Larsen et al attempted to assess the impact of the EUS-FNA procedure on clinical outcomes in their patients. A board of thoracic specialists reviewed the history of each patient up to the point of referral for EUS-FNA and was asked to decide on further management if EUS had not been available. This strategy was then compared with the actual clinical course after the procedure. In addition to the eight patients found to have small cell lung cancer resulting in referral for chemotherapy, a further three were found to have a specific benign diagnosis (sarcoidosis, mediastinal abscess, and oesophageal leiomyoma) and were managed accordingly. Comparing actual with planned management, if EUS had not been available, 28 of 41 mediastinoscopies $(68 \%)$ and 18 of 37 thoracotomies (49\%) were avoided because of the information gained from the procedure. One potential drawback with this approach is the possibility of bias, as the study authors themselves formed the panel assessing the impact of the test in question. A truly independent panel working to predefined criteria would have made the findings more robust. Although no cost effectiveness data were presented, it seems likely that an EUS-FNA strategy would have had significant cost savings, in keeping with the result of other studies. ${ }^{13}$

\section{"EUS-FNA should have a central role in the investigation of patients with mediastinal masses"}

So where do we go from here? The results of this and other studies suggest that EUS-FNA should have a central role in the investigation of patients with mediastinal masses and the staging of those with potentially resectable lung cancer, but many questions remain. Firstly, where exactly in the investigative 
algorithm should it occur? Patients with node positive CT scans at levels $5,7,8$ or 9 should probably undergo EUS-FNA before mediastinoscopy for histological confirmation. However, despite the high sensitivity of EUS-FNA and its ability to resolve small nodes, it has not so far been found to be of routine value in patients with node negative CT imaging. Secondly, how does EUS compare with PET scanning? Comparative studies are still awaited but preliminary evidence suggests an advantage in favour of EUS, largely because of false positive results with PET. ${ }^{14}$ Thirdly, who should perform EUS-FNA and where should it be done? The equipment is expensive and the learning curve relatively steep. The procedure is usually performed for other indications by gastroenterologists who know little of the mediastinum and only see it when an unfortunate oesophageal perforation occurs! Training in upper gastrointestinal endoscopy is required, a skill that few if any bronchoscopists currently have. However, this has not deterred many cardiologists from learning the techniques of transoesophageal echocardiography. Perhaps it does not matter who performs the procedure as long as it is done accurately, safely, and efficiently, but for the time being it is likely to remain in the realm of the gastrointestinal endoscopist or endoscoping radiologist.

Carefully designed prospective studies are required to answer these questions and, as in the study by Larsen et al, these should include end points such as cost effectiveness, overall patient tolerability, and quality of life. The information from such work will hopefully help to guide clinicians who manage patients with mediastinal malignancy and would appear to have the potential of saving a significant number of invasive procedures.

Thorax 2002;57:95-96

\section{Authors' affiliations \\ I Penman, R J Fergusson, Western General Hospital, Crewe Road, Edinburgh EH4 2XU, UK \\ Correspondence to: Dr R J Fergusson; \\ ron.fergusson@luht.scot.nhs.uk \\ REFERENCES \\ 1 Mountain CF. Revisions in the international system for staging lung cancer. Chest 1997;111:1711-7. \\ 2 McLoud TC, Bourgouin PM, Greenberg RW, et al. Bronchogenic carcinoma: analysis of staging in the mediastinum with CT by correlative lymph node mapping and sampling. Radiology 1992;182:319-23. \\ 3 Arita T, Kuramitsu T, Kawamura M, et al. Bronchogenic carcinoma: incidence of metastases to normal sized lymph nodes. Thorax 1995:50:1267-9. \\ 4 Gress FG, Savides TJ, Sandler A, et al. Endoscopic ultrasonography, fine-needle aspiration biopsy guided by endoscopic ultrasonography, and computed tomography in the preoperative staging of non-small-cell lung cancer: a comparison study. Ann Intern Med 1997; 127:604-12 \\ 5 Silvestri GA, Hoffman BJ, Bhutani MS, et al. Endoscopic ultrasound with fine-needle aspiration in the diagnosis and staging of lung cancer. Ann Thorac Surg 1996;61:1441-6. \\ 6 Hawes RH, Gress F, Kesler K, et al. Endosocpic ultrasound versus computed}

tomography in the evaluation of the mediastinum in patients with non-small-cell lung cancer. Endoscopy 1994;26:784-7.

7 Williams DB, Sahai AV, Aabakken L, et al. Endoscopic ultrasound guided fine needle aspiration biopsy: a large single center experience. Gut 1999;44:720-6.

8 Hunerbein M, Ghadimi BM, Haensch W, et al. Transoesophageal biopsy of mediastinal and pulmonary tumors by means of endoscopic guidance. J Thorac Cardiovasc Surg 1998;116:554-9.

9 Wiersema MJ, Hawes RH, Tao LC, et al. Endoscopic ultrasonography as an adjunct to fine-needle aspiration cytology of the upper and lower gastrointestinal tract. Gastrointest Endosc 1992;38:35-9.

10 Wiersema MJ, Vilmann P, Giovannini M, et al. Endosonography-guided fine-needle aspiration biopsy: diagnostic accuracy and complication assessment. Gastroenterology 1997; 112:1087-95.

11 Wiersema MJ, Edell ES, Midthun DE, et al. A blinded prospective study comparing transbronchial needle aspiration (TBNA) and endosonography guided needle aspiration (EUS FNA) in the staging of mediastinal lymphadenopathy in patients with non small cell lung cancer. Gastrointest Endosc 2001;53:AB556.

12 Larsen SS, Krasnik M, Vilmann P, et al. Endoscopic ultrasound guided biopsy of mediastinal lesions has a major impact on patient management. Thorax 2002;57:98-103.

13 Aabakken L, Silvestri GA, Hawes R, et al. Cost-efficacy of endoscopic ultrasonography with fine-needle aspiration vs. mediastinotomy in patients with lung cancer and suspected mediastinal adenopathy. Endoscopy 1999:31:707-11.

14 Fritscher-Ravens A, Hauber H-P, Bohuslavizki K, et al. Role of endoscopic ultrasound with fine needle aspiration (EUS-FNA) versus positron emission tomography (PET) for deciding operability of lung cancer patients. Gastrointest Endosc 2001;53:AB4182. and army recruits ${ }^{910}$ provide ready sources of young adults for study. However, although such cross sectional studies demonstrate very clearly that adolescence is a time when significant changes occur in the asthmatic population, they cannot examine the factors that might influence the prognosis of individual children.

There have, of course, been longitudinal studies-notably those from Melbourne, ${ }^{11}$ Groningen, ${ }^{13}$ and Copenhagen ${ }^{14}$-all of which have emphasised the importance of childhood bronchial hyperreactivity in determining the persistence of asthmatic symptoms into adult life. However, most of these studies have been incomplete to varying degrees, different studies focusing on asthmatic symptoms, family history, pulmonary function, bronchial hyperreactivity to a variety of stimuli, and allergic phenomena including IgE levels and the results of skin tests. What has been lacking is a study in which children have 
been subject to comprehensive evaluation of what is sometimes described as the "asthma phenotype" at regular intervals during childhood, through adolescence, and into adulthood.

Some years ago the late Ann Woolcock posed the question: "Is there a specific phenotype for asthma?"15 Of course there isn't, but rather there is a group of clinical features that are seen with varying frequencies in children in whom a diagnosis of asthma has been made. Virtually all will have had recurrent wheeze, with the exception of those rare children with cough variant asthma, and virtually all will have evidence of reversible airways obstruction if seen during an attack. Many (but not all) will show evidence of allergy, with associated eczema or hay fever, positive skin tests, or raised total or specific IgE levels. The more severely affected will show bronchial hyperreactivity in response to challenges such as cold air, exercise, or nebulised water, saline, histamine, methacholine, or allergen. There will be direct or indirect evidence of bronchial inflammation, although such measurements have not yet been simplified sufficiently for use in epidemiological studies. And, of course, many will have a family history of asthma or allergy.

The interactions between these various components of the asthma phenotype are complex. Thus, bronchial hyperreactivity appears to be inherited independently of atopy, ${ }^{16}$ yet it is not only closely associated with the severity of asthmatic symptoms ${ }^{17}$ but also correlates with the number of positive skin tests. ${ }^{18}$

In an attempt to evaluate the relative importance of these asthmatic features in determining the long term course of childhood asthma, a paper by Professor Woolcock and her colleagues in this issue of Thorax reports on data collected from a series of studies performed in Belmont, New South Wales. ${ }^{19}$ The subjects in this study have been investigated extensively on a maximum of seven occasions and were included in the present analysis if studied on a minimum of three occasions.

The results make fascinating reading. More than one third of the subjects had had recent wheeze in at least one of the studies and, although remission did occur, the rate of remission was less than the incidence of new cases-so much for asthma disappearing at puberty! Atopy also tended to accumulate with a higher incidence than remission rates. In contrast, bronchial hyperreactivity did remit, and did so at a substantially faster rate than the incidence of new cases.
However, the real fascination of this paper is in the examination of risk factors for persistence of wheeze and for late onset wheeze. There is no need to repeat the contents of the paper here; suffice it to say that we now have information that will be potentially useful to practising clinicians whose patients ask those awkward and hitherto unanswerable questions about their future. Unfortunately, these prognostications depend, to a large extent, on the assessment of bronchial hyperreactivity, a time consuming procedure using materials that are not even licensed for the purpose and which few of us have the resources to include in the routine assessment of asthmatic patients.

The greatest value of this study will therefore be to research workers. Numerous interesting questions are raised. Why, for instance, is being female a risk factor for late onset bronchial hyperreactivity, but being male a risk factor for late onset atopy? The sex difference for childhood asthma is narrowing ${ }^{20}$ and these unexplained gender differences may shed some light on the current "epidemic" of asthma and why it has apparently peaked, ${ }^{21}$ if indeed it has. ${ }^{22}$ And why should early onset atopy be a greater risk factor for subsequent wheeze than late onset atopy? It is clear that the genes have a lot to answer for; other things being equal, a positive family history of asthma continues to be an independent risk factor well into adult life.

This paper will provoke much discussion and will undoubtedly stimulate further research. It is enormously sad that the senior author did not survive to see it published

\section{Thorax 2002;57:96-97}

\section{Author's affiliation}

G Russell, Department of Child Health, University of Aberdeen, Aberdeen AB9 2ZG, UK

Correspondence to: $\operatorname{Dr} G$ Russell;

libra@ifb.co.uk

\section{REFERENCES}

1 Blair H. Natural history of childhood asthma 20-year follow-up. Arch Dis Child 1977;52:613-9.

2 Martin AJ, Landau LI, Phelan PD. Natura history of allergy in asthmatic children followed to adult life. Med J Aust $1981 ; 2: 470-4$

3 Cserhati E, Mezei G, Kelemen J. Late prognosis of bronchial asthma in children. Respiration 1984:46: 160-5.

4 Fagan JK, Scheff PA, Hryhorczuk D, et al. Prevalence of asthma and other allergic diseases in an adolescent population: association with gender and race. Ann Allergy Asthma Immunol 200 1;86:177-84

5 De Marco R, Locatelli F, Sunyer J, et al. Differences in incidence of reported asthma related to age in men and women. A retrospective analysis of the data of the European Respiratory Health Survey. Am J Respir Crit Care Med 2000;162:68-74.

6 Worldwide variations in the prevalence of asthma symptoms: the International Study of Asthma and Allergies in Childhood (ISAAC). Eur Respir J 1998;12:315-35.

7 Garcia-Gonzalez JJ, Vega-Chicote JM, Rico $\mathrm{P}$, et al. Prevalence of atopy in students from Malaga, Spain. Ann Allergy Asthma Immunol 1998;80:237-44

8 Settipane GA, Greisner WA III, Settipane RJ. Natural history of asthma: a 23-year followup of college students. Ann Allergy Asthma Immunol 2000;84:499-503.

9 Dubois $\mathbf{P}$, Degrave E, Vandenplas O. Asthma and airway hyperresponsiveness among Belgian conscripts, 1978-91. Thorax 1998;53:101-5.

10 Noriavaara E, Gerhardsson DV, Lindmark B. Reduced height in Swedish men with asthma at the age of conscription for military service. J Pediatr 2000;137:25-9.

11 Kelly WJ, Hudson I, Phelan PD, et al. Childhood asthma in adult life: a further study at 28 years of age. BM (Clin Res Ed) 1987;294: 1059-62.

12 Phelan PD. Hyperresponsiveness as a determinant of the outcome in childhood asthma. Am Rev Respir Dis 1991;143:1463-6; discussion 1466-7.

13 Roorda RJ, Gerritsen J, van Aalderen WM, et al. Risk factors for the persistence of respiratory symptoms in childhood asthma. Am Rev Respir Dis 1993;148:1490-5.

14 Ulrik CS, Backer V, Hesse B, et al. Risk factors for development of asthma in children and adolescents: findings from a longitudinal population study. Respir Med 1996;90:623-30.

15 Woolcock AJ, King G. Is there a specific phenotype for asthma? Clin Exp Allergy 1995;25(Suppl 2):3-7.

16 Gray L, Peat JK, Belousova E, et al. Family patterns of asthma, atopy and airway hyperresponsiveness: an epidemiologica study. Clin Exp Allergy 2000;30:393-9.

17 Gustafsson PM, Kjellman B. Asthma from childhood to adulthood: course and outcome of lung function. Respir Med 2000;94:466-74.

18 Lombardi C, Passalacqua G, Ciprandi G, et al. Relationship between degree of nonspecific hyperresponsiveness and number of positive skin tests in asthmatics. Monaldi Arch Chest Dis 2000;55:181-4.

19 Xuan W, Marks GB, Toelle BG, et al. Risk factors for onset and remission of atopy, wheeze, and airway hyperresponsiveness. Thorax 2002;57: 104-9.

20 Anthracopoulos M, Karatza A, Liolios E, et al. Prevalence of asthma among schoolchildren in Patras, Greece: three surveys over 20 years. Thorax 2001;56:569-71.

21 Ronchetti R, Villa MP, Barreto $M$, et al. Is the increase in childhood asthma coming to an end? Findings from three surveys of schoolchildren in Rome, Italy. Eur Respir J 2001;17:881-6.

22 Downs SH, Marks GB, Sporik R, et al. Continued increase in the prevalence of asthma and atopy. Arch Dis Child 2001;84:20-3. 